\title{
Lung Cancer: Facts, Figures and Reflections on Spending
}

\author{
Usman Ahmad $^{1}$, Michael Ruschel ${ }^{2}$, Frank C. Detterbeck ${ }^{1^{*}}$ \\ ${ }^{1}$ Department of Thoracic Surgery, Yale New Haven Hospital, Yale University School of Medicine, New Haven, USA; ${ }^{2}$ School of \\ Medicine, Universitat Leipzig, Leipzig, Germany. \\ Email: usman.ahmad@yale.edu, michael.ruschel@gogglemail.com, *frank.detterbeck@yale.edu
}

Received January $10^{\text {th }}, 2012$; revised February $20^{\text {th }}$, 2012; accepted March $15^{\text {th }}, 2012$

\begin{abstract}
The war on cancer was declared 40 years ago. While the potential for reducing deaths is increasing, so are the costs. Finding the right prioritization in our complex world is difficult; we present some interesting facts regarding other wars and aspects of society that are worth reflecting on as we struggle to find the right balance.
\end{abstract}

Keywords: Lung Cancer; Costs; Screening

\section{Introduction}

We live in a time when we must be increasingly thoughtful about the costs of medical interventions. It is increasingly apparent that rising costs of healthcare put a strain on the economy, and that simply spending more for healthcare does not linearly correlate with better outcomes. At the same time, advances in diagnostic and therapeutic technology continue to progress at accelerating speeds. While exciting and often very useful, these come at the price of ever increasing costs.

In considering these issues, we have chosen to focus on lung cancer for several reasons, including personal interest and involvement in this field. Lung cancer is by far the leading cause of cancer deaths, accounting for more deaths than the next 4 leading causes of cancer deaths combined (colon, breast, prostate and pancreas) [1]. Furthermore, there are several indications that lung cancer is undergoing fundamental changes. We must consider whether and how to implement CT screening for lung cancer. The National Lung Cancer Screening Trial has shown a dramatic $20 \%$ reduction in lung cancer mortality [2]; however we must consider the costs of a screening CT, additional diagnostic and evaluation costs as well as potential cost savings from a decreased incidence of stage IV cancers. The chemotherapy management of lung cancer is shifting towards more treatment with targeted therapy defined by specific genetic mutations; these are associated with high costs, and often prolonged courses of therapy. Modern radiotherapy often involves higher-doses delivered using more expensive techniques such as Intensity-Modulated Radiation Therapy. Studies are showing that an aggressive approach

${ }^{*}$ Corresponding author. offers better palliation even when cure is not possible. The attitude of nihilism about lung cancer is giving way to enthusiastic engagement in a previously neglected disease. The constellation of these issues positions lung cancer at a focal point in the struggle to find a balance between promoting advances and managing costs.

\section{Deaths and Spending in the War on Cancer and Other Major Wars}

Technology and science are advancing at a rapid pace, and this has a major impact on improving our lives and also on saving lives. A comparison of the cost and the number of casualties among major US wars (Figure 1(a)) shows that in each subsequent war dramatically fewer lives are lost, but at an increasing cost $[3,4]$. Surely this is due to increasing investment on weapons technology. It is also apparent that in recent years the rate of change (both increasing costs and decreasing the lives lost) has accelerated dramatically.

How does the war on cancer, declared by President Nixon in 1971, measure up against other wars? Ironically, while cancer claims in several orders of magnitude more lives lost than any of the previous or ongoing wars it has received relatively the least amount of resources. Because of differences in the duration of wars, it is probably more appropriate to look at measures other than total costs, such as annual costs (Figure 1(b)).

In terms of dollars spent per death (Figure 1(c)), cancer related expenditure is 500 times less than that of any war in the last 50 years, although cancer is costing more lives every day as compared to any other war and about 500 times more than recent wars. Even with respect to research investment there is a marked disparity. In FY- 


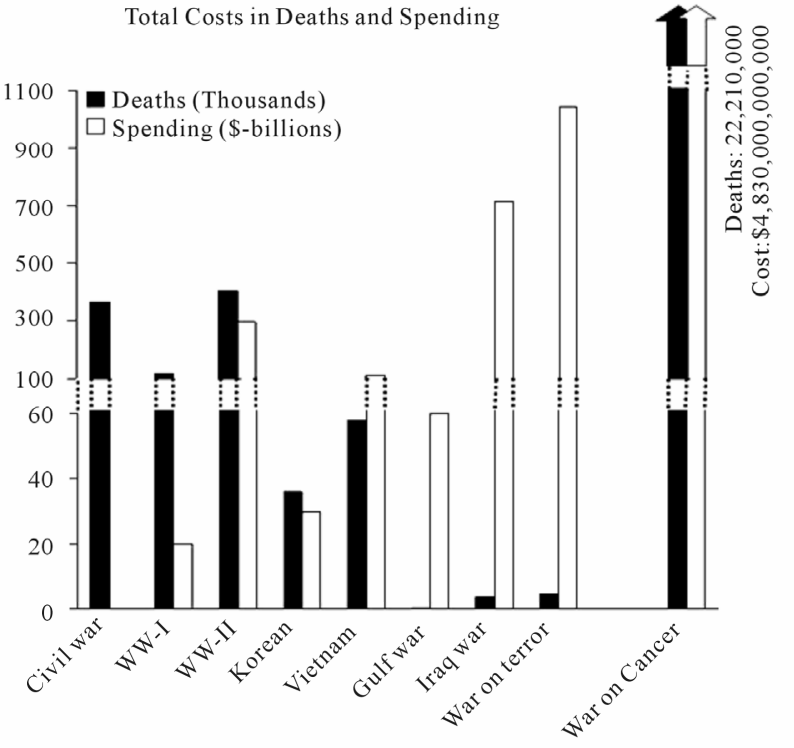

(a)

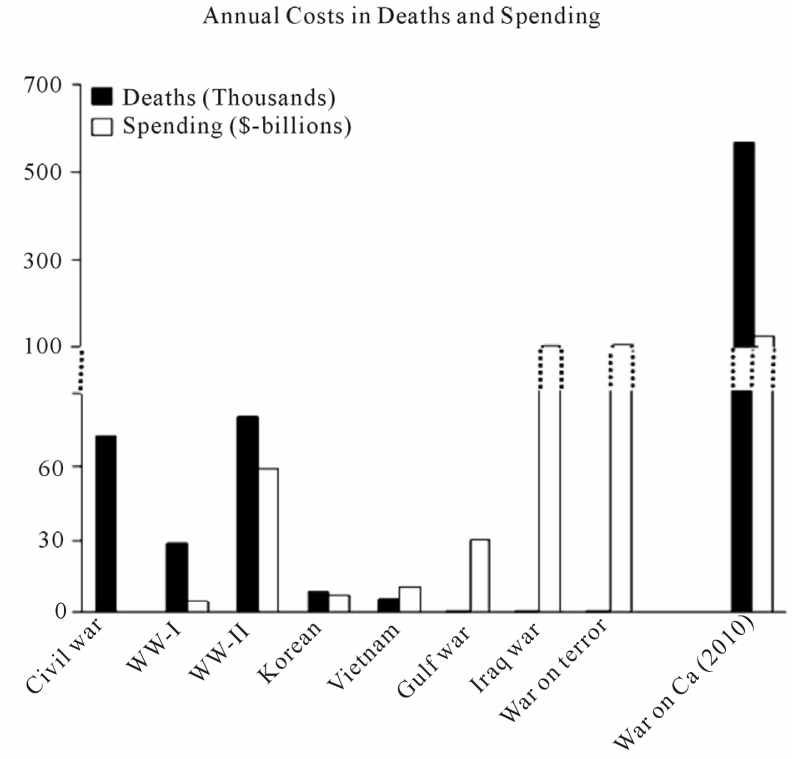

(b)

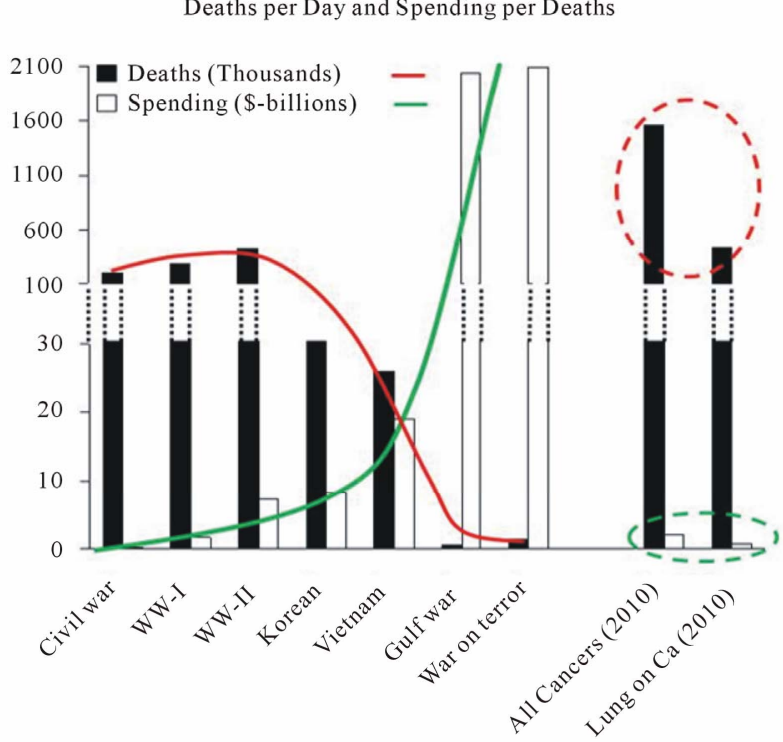

(c)

Figure 1. (a) Comparison of overall mortality and cost of major US wars. Figures are as reported by the US Department of Defense [3,4]. Deaths and costs of civil war shown are of the Union only. Ongoing wars (i.e. terror, cancer) are total costs as of the end of 2010. Estimated total cancer deaths since 1971 are 22,210 thousand, while the estimated amount spent on cancer is 4830 billion dollars [1,8]; (b) Annual cost and mortality of major US wars as compared to cancer (averaged over the duration of the war). Figures for cancer mortality and cost are for the year $2010[1,3,4,8]$; (c) Daily deaths and spending per death in major US wars as compared to all cancers and lung cancer. The figures for cancer mortality and cost are for the year 2010 $[1,3,4,8]$.

2010, \$76 billion were allocated only to military "Research, Development, Testing and Evaluation" [5] (with roughly 600 US military deaths occurring in this time period), while the total FY-2010 National Cancer Institute (NCI) budget was $\$ 5.1$ billion [6] (with nearly 600,000 cancer-related deaths occurring during this time).

\section{Comparison of Deaths and Research Spending in Major Cancer Types}

A comparison among cancer types also suggests that our funding priorities are not determined by the number of lives lost. In Figure 2, the proportion of deaths among the 5 leading causes of cancer deaths are compared with 


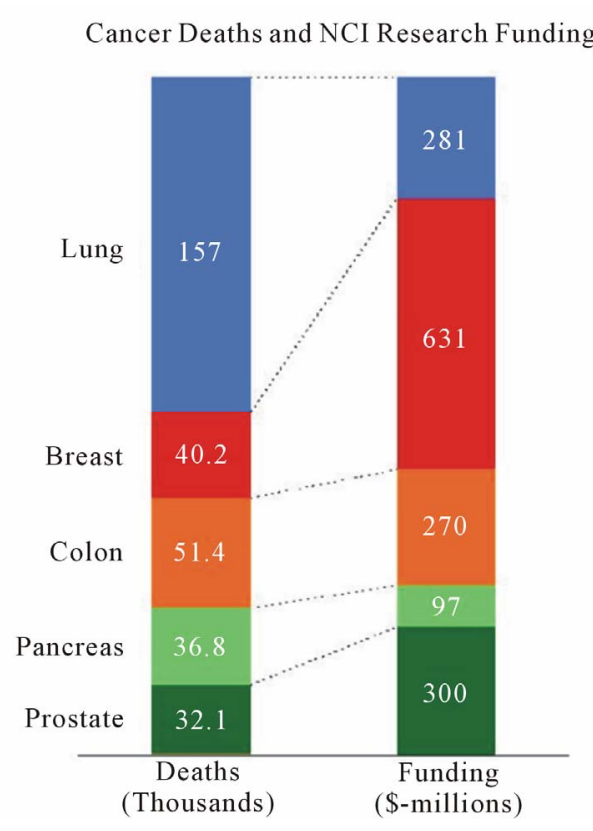

Figure 2. Comparison of number of annual deaths (thousands) to proportion of annual NCI research funding (\$millions). Figures are for the year 2010 [6].

the proportion of NCI research funding.

Breast cancer has received about $\$ 15,700$ per breast cancer death, while for lung cancer it is only $\$ 1800$ per lung cancer death. In 2010, there were 222,520 new di- agnosed cases of lung cancer while that of breast cancer were 209,060 [1]. One can argue that the funding should go to areas where there is the most progress, and that there have been more treatment advances in breast cancer than in lung cancer. However, it is more likely that the lack of progress in lung cancer is due to the lack of funding rather than the other way around.

\section{Lung Cancer and Other Healthcare-Related Expenditures}

Another assessment of our priorities can be made from assessing several costs and outlays relative to healthcare and lung cancer, as shown in Figure 3.

While the healthcare costs of cigarette smoking are huge, the amount spent on smoking cessation is only about $0.5 \%$ of the overall healthcare costs of smoking. Similarly, only about $2.3 \%$ of the costs of lung cancer care are spent on research to improve this care. Furthermore, the amount of spending for lung cancer research is minimal (2\%) compared to tobacco company outlays for marketing and lobbying [7]. Spending on lung cancer research is also minimal compared to public out-ofpocket spending for complementary medicine, or health insurance company profits.

However, one cannot justify increased spending on lung cancer by pointing to areas with a relatively higher degree of funding. Unless there is a mechanism to ra-

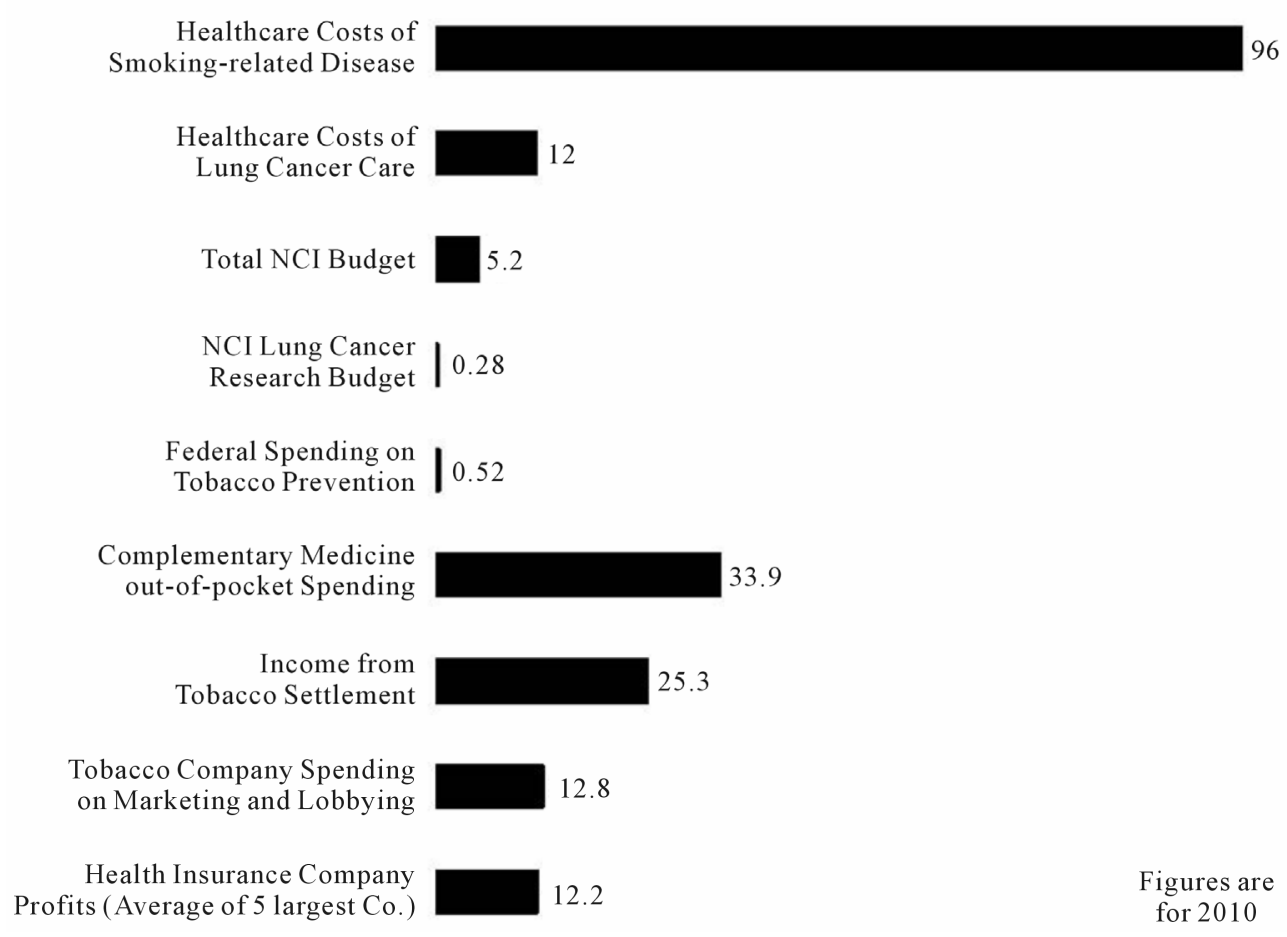

Figure 3. Smoking related and other interesting figures. Figures are for the year 2010 [7]. 
tionally balance funding, this sort of approach leads to endless escalation of overall costs. Furthermore, comparisons of different causes of deaths (i.e. cancer and military) ignore many societal and personal values and implications. Finding the right balance of funding is clearly a difficult, complex issue, with multiple stakeholders and viewpoints, and with multiple implications, most of which are poorly understood. Nevertheless, as we consider issues such as CT screening or drug development research for lung cancer in the coming months and years, the comparisons noted here are worth reflecting upon.

\section{REFERENCES}

[1] A. Jemal, R. Siegel, J. Xu, et al., “Cancer Statistics,” CA: Cancer Journal for Clinicians, Vol. 60, No. 5, 2010, pp. 277-300. doi:10.3322/caac.20073

[2] The National Lung Screening Trial Research Team, "Reduced Lung-Cancer Mortality with Low-Dose Computed Tomographic Screeing," New England Journal of Medicine, Vol. 365, No. 26, 2011, pp. 395-409.
doi:10.1056/NEJMoa1102873

[3] S. Daggett, “Cost of Major U.S. Wars,” Congressional Research Service Report RS22926, 2010.

[4] A. Leland and M.-J. Oboroceanu, "American War and Military Operations Casualties: Lists and Statistics,” Congressional Research Service Report RL32492, 2010.

[5] "Historical Tables: Office of Management and Budget, Table 3.2., Outlays by Function and Subfunction: 1962-2016,” Accessed on 7 February 2011. http://ww.whitehouse.gov/omb/budget/Historicals

[6] National Cancer Institute, “2010 Fact Book,” U.S. Department of Health and Human Services, National Institute of Health, Bethesda, Maryland. http://obf.cancer.gov

[7] "Federal Trade Commission Cigarette Report for 2006," 2009. http://www.ftc.gov/os/2009/08/

[8] A. B. Mariotto, K. R. Yabroff, Y. Shao, et al., "Projections of the Cost of Cancer Care in the United States: 2010-2020," Journal of the National Cancer Institute, Vol. 103, No. 2, 2011, pp. 117-128. doi:10.1093/jnci/djq495 